\title{
ENSINO DE ARTE NA ESCOLA BILÍNGUE: RELATO SOBRE EXPERIÊNCIA COM A PROPOSTA TRIANGULAR NA EDUCAÇÃO DE SURDOS
}

\author{
ART EDUCATION IN THE BILINGUAL SCHOOL: REPORT ON \\ EXPERIENCE WITH THE TRIANGULAR PROPOSAL ON \\ EDUCATION OF DEAF
}

DOI: http://dx.doi.org/10.5965/1984317813022017179

Sandra Maria Silva Oliveira, Suelene Regina Donola Mendonça - UNITAU

\section{RESUMO}

O presente texto pretende relatar a experiência de uma professora de Arte em uma escola pública municipal bilíngue para surdos no interior do estado do Rio de Janeiro. O relato objetiva apresentar e discutir a experiência da docente no ensino da Arte com os alunos surdos dessa escola. Com base na proposta Triangular de Ana Mae Barbosa, cujo tema foi impressionismo, buscou-se refletir sobre os desafios e possibilidades no ensino da Arte, mais especificamente o ensino do movimento artístico impressionista para alunos surdos dessa instituição, a partir da leitura e releitura de imagens. Os resultados apontam que nesse contexto, não obstante as diferenças presentes na comunicação, houve interação, troca e produção de conhecimento. Destaca-se ainda a relevância da Libras para o processo de acesso as informações e ao conhecimento. Espera-se que esse trabalho possa contribuir para futuras discussões sobre o ensino de Arte para alunos surdos.

Palavras-chave: Ensino de Arte. Proposta Triangular. Educação Inclusiva de Surdos.

\begin{abstract}
The present text intends to report the experience of an Art teacher in a bilingual municipal public school for the deaf in the interior of Rio de Janeiro. The report aims to present and discuss the experience of the teacher in the teaching of Art with the deaf students of this school. Based on the Triangular proposal by Ana Mae Barbosa, whose theme was Impressionism, we sought to reflect on the challenges and possibilities in the teaching of Art, more specifically the teaching of the Impressionist artistic movement for deaf students of this institution, from reading and re-reading images. The results indicate that in this context, despite the differences present in the communication, there was interaction, exchange and knowledge production. It is also worth highlighting the importance of Libras for the process of access to information and knowledge. It is hoped that this work may contribute to future discussions about Art education for deaf students.
\end{abstract}

Keywords: Teaching of Art. Triangular Proposal. Education of the deaf. 


\section{INTRODUÇÃO}

O presente relato tem como objetivo descrever uma experiência da professora de Arte de uma escola bilíngue da rede pública municipal de educação de ensino fundamental, situada numa cidade do interior do estado do Rio de Janeiro, que atende alunos surdos e ouvintes, pois quando escrevemos sobre o que fazemos na sala de aula temos um excelente procedimento para a conscientização dos nossos padrões e também das limitações nesse trabalho (ZABALZA, 2004).

Esta escola, pioneira no município no oferecimento da educação para surdos, insere alunos ouvintes onde a sua maioria é surda. Esta concepção proporcionou, segundo os orientadores pedagógicos do estabelecimento, ganhos educacionais, pedagógicos, sociais e afetivos, tanto para o grupo de alunos surdos, quanto para os alunos ouvintes ali inseridos. Partindo do princípio do direito a educação, a escola bilíngue deve assegurar este direito oferecendo uma grade curricular idêntica a do ensino regular, entretanto deve ter como diferencial o ensino e uso de Libras (Língua Brasileira de Sinais), por todos da instituição, por isso a escola disponibiliza um curso de Libras permanente para toda a comunidade escolar.

O desafio estabelecido foi o ensino da Arte aos alunos surdos dessa escola, considerando as especificidades dos mesmos em relação a língua utilizada, bem como as limitações da própria professora a respeito desse universo.

A partir das observações e características presentes neste contexto, algumas questões provocaram a professora sobre ensino e aprendizagem dos alunos surdos: quais estratégias de trabalho a disciplina de Arte poderia utilizar de modo a possibilitar a aprendizagem dos alunos? Seria a comunicação por meio da leitura de imagem de obras de arte uma forma de propiciar a aprendizagem para os alunos desta escola?

Para tentar responder estes questionamentos, foi desenvolvida uma experiência de construção de conhecimentos a partir da releitura como prática de ensino de arte nesta escola bilíngue para os alunos, cujo tema foi o impressionismo, conteúdo programático do currículo escolar. 
Assim para desenvolver o tema impressionismo com seis alunos surdos do $8^{\circ}$ ano escolar, foi utilizada a Proposta ou Abordagem Triangular desenvolvida por Ana Mae Barbosa, a principal referência no Brasil para o ensino da Arte nas escolas, tendo sido a primeira brasileira com doutorado em Arte-educação, defendido em 1977, na Universidade de Boston, e que tem como princípio norteador conhecer a história da arte, e a partir das obras e seus respectivos artistas presentes no espaço/tempo recortado, realizar a leitura de imagem e então buscar um fazer artístico, (a releitura) contextualizado com as etapas anteriores. Este texto é o relato desta experiência.

\section{REFERENCIAL TEÓRICO}

\subsection{A arte como conhecimento e experiência de vida}

Cada um de nós possui uma bagagem de conhecimentos relativos a nossa experiência de vida, e com os alunos não é diferente. E quando estes alunos têm oportunidade de relacionar seu conhecimento de mundo às imagens das obras de arte e se apropriar dos saberes que uma mediação entre tais imagens e suas experiências, este enriquecimento não só é positivo como necessário para seu desenvolvimento crítico, pois as mensagens que são decodificadas geram significados e interpretações das mais diversas. Segundo Ana Mae Barbosa (1999):

Quando se diz em conhecer arte, fala-se de um conhecimento que nas artes visuais se organiza inter-relacionando o fazer artístico, a história da arte e sua apreciação; esse conhecimento em artes se dá na interseção da experimentação, da codificação e da informação. Só um fazer consciente e informado torna possível a aprendizagem em arte (BARBOSA, 1999, p.31$32)$.

Ainda sobre o conhecimento que a Arte pode propiciar, Vygostsky, em seu livro "Psicologia da Arte" apresenta as conexões relacionadas à arte na educação, contribuindo sobremaneira no presente estudo. Segundo o autor, o significado da arte está relacionado a nossa própria vida:

Ainda nos resta examinar a questão do significado que a arte adquire [...]. Neste sentido, qual é a relação da reação estética com todas as outras reações do homem, como, à luz dessa interpretação, elucidam-se o papel e o 
significado da arte no sistema geral do comportamento humano? E se quisermos resolver o problema da relação entre arte e vida, se quisermos colocar o problema da arte no plano da psicologia aplicada, deveremos estar munidos de alguma concepção teórica geral que nos permita uma base sólida para a solução desta questão (VYGOTSKY, 1999, p. 303).

Para Vygotsky (1999) não basta estar em contato com a arte, é preciso vivenciá-la pois ela faz parte do ser humano, e por isso é tão relevante seu significado para o mesmo. Seu livro aborda ainda do papel social da arte, de como ele nos é significativo também, pontuando sobre seu sentido psicossocial:

Se tentarmos elucidar o sentido social da arte, [...] A arte é o social em nós, e se o seu efeito se processa em um indivíduo isolado, isto não significa, de maneira nenhuma, que as suas raízes e essência sejam individuais. É muito ingênuo interpretar o social apenas como coletivo, como existência de uma multiplicidade de pessoas. O social existe até onde há apenas um homem e suas emoções pessoais (VYGOTSKY, 1999, p. 315).

Ainda sobre seus apontamentos, o autor diz que vivenciamos a arte, e podemos ampliar esse entendimento a partir das várias linguagens artísticas, experimentando estas abordagens no sentido do individual para o social: isto quer dizer que a arte permite ao indivíduo, que através dela a experiência ou fenômeno artístico vai conferir seu fazer/sentir pessoal desdobrar-se em social.

Arte é uma técnica social do sentimento, um instrumento da sociedade através do qual incorpora ao ciclo da vida social aspectos mais íntimos e pessoais do nosso ser. Seria mais correto dizer que o sentimento não torna social mas, ao contrário, torna-se pessoal, quando cada um de nós vivencia uma obra de arte, converte-se em pessoal sem com isso deixar de continuar social (VYGOTSKY, 1999, p. 315).

Em seu estudo, Vygotsky (1999) nos faz refletir sobre a questão do nosso comportamento quando estamos em contato com as linguagens da arte. Ele nos mostra que a arte precisa de nossa interação, ela se faz necessária para que esta experiência se realize, numa noção de que a vida pulsa em nós através destas experiências: 


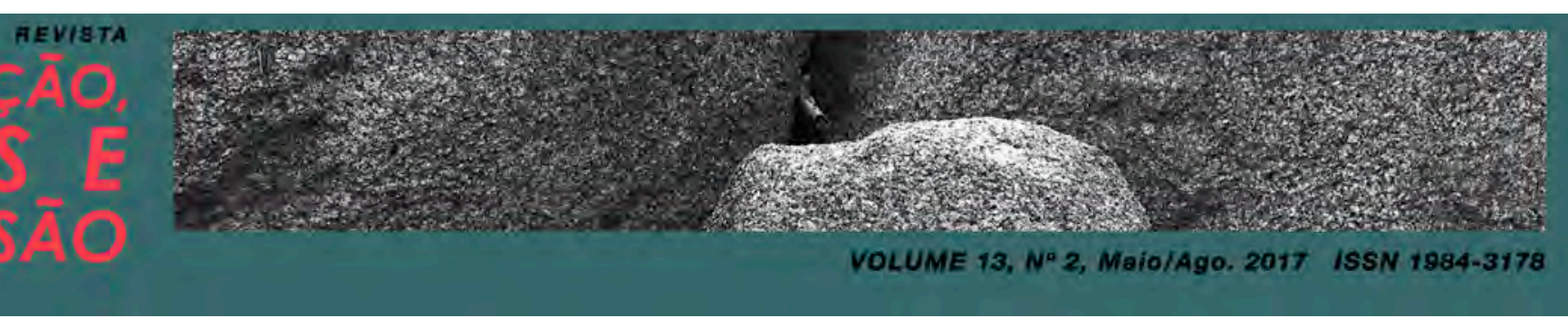

\begin{abstract}
A arte é antes uma organização do nosso comportamento visando o futuro, uma orientação para o futuro, uma exigência que talvez nunca venha a concretizar-se, mas que nos leva a aspirar acima da nossa vida o que está por trás dela.[...] Tudo o que a arte realiza, ela o faz no nosso corpo e através dele (VYGOTSKY, 1999, p. 320).
\end{abstract}

É por essa razão que o autor vai defender o ensino da arte na educação, pois que ela está presente desde sempre na história da humanidade, desde a antiguidade que a arte tem sido considerada como "um meio e um recurso da educação, isto é, como certa modificação duradoura do nosso comportamento e do nosso organismo" (VYGOTSKY, 1999, p. 321). A arte e o comportamento humano, pesquisados pelo autor através da psicologia, revelam o caráter pedagógico e educativo da disciplina e sua significativa contribuição. Segundo o autor, todo o valor da arte se vê reduzido ao "efeito educativo, e todos os autores que percebem uma afinidade entre a pedagogia e a arte veem inesperadamente o seu pensamento confirmado pela análise psicológica" (1999, p. 321). Seus estudos apontam também que não se pode ensinar a criatividade, ela é estimulada por processos inconscientes, e o fazer artístico propicia esta condição:

[...] que o ato artístico é um ato criador e não pode ser recriado por meio de operações puramente conscientes; contudo, se o mais importante na arte se reduz ao momento e forças conscientes foram inteiramente suprimidos desse momento? Ensinar o ato criador da arte é impossível; entretanto, isto não significa, em absoluto, que o educador não pode contribuir para a sua formação e manifestação. Através da consciência penetramos no inconsciente, de certo modo podemos organizar os processos conscientes de maneira a suscitar através deles os processos inconscientes, e todo o mundo sabe que qualquer ato artístico incorpora forçosamente como condição obrigatória os atos de conhecimento racional precedentes, as concepções, identificações, associações, etc. (VYGOTSKY,1999, p. 325).

Partindo de suas considerações, podemos dizer que a arte é a mais "importante concentração de todos os processos biológicos e sociais do indivíduo na sociedade, um meio de equilibrar o homem com o mundo nos momentos mais críticos responsáveis da vida" (VYGOTSKY, 1999, p. 329). Entendemos aqui que a arte está completamente conectada ao ser humano, quando o mesmo é um ser individual, mas que habita e transita no social. 


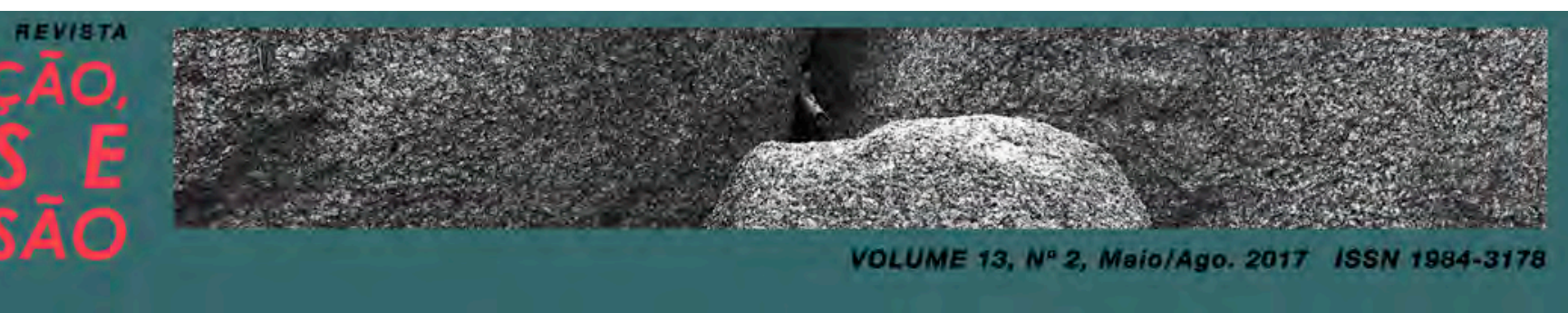

\subsection{A Educação Bilíngue}

Entretanto, o grande desafio encontrado pela docente ao chegar nesta escola foi a comunicação. Esta, por sua vez deve acontecer a partir do uso da LIBRAS (Lingua Brasileira de Sinais) "cuja modalidade de recepção e produção é viso-gestual" (SKLIAR, 1998, p. 49). Partindo do princípio que a comunicação entre as pessoas é fundamental, pois "que as línguas 'faladas' por qualquer grupo social constituem importantíssimos meios de comunicação entre os seres humanos não resta a menor dúvida" (PUPPI, 2009, p. 19). Segundo esta afirmativa, a língua se faz necessária e é importante para que a comunicação ocorra entre os sujeitos e, assim, dentro do contexto escolar, imprescindível para que o processo de ensino possa se efetivar. Numa escola bilíngue para surdos a língua de sinais deve ser a primeira língua de comunicação e expressão dos surdos, o "bilinguismo na área da educação dos surdos deveria aludir à sua acepção pedagógica, isto é, à ideia de educação bilíngue, ao direito dos sujeitos que possuem uma língua minoritária de serem educados nessa língua” (SKLIAR, 1998, p. 54). Essa língua de caráter viso-gestual deve então ser aquela em que os conteúdos de todas as disciplinas devem ser aplicados. Para a compreensão de como se efetiva a aprendizagem, convém definir as formas de comunicação e linguagem que ocorrem neste contexto escolar: Podemos compreender a comunicação em Libras como fenômeno linguístico através dos estudos de Saussure, onde fala que existe "algo comum entre todas as línguas,(...) e cada língua em particular possui seu sistema de signos" (PUPPI, 2009, p. 74). Assim definindo que a comunicação precisa se articular através dos signos presentes nas línguas. "Estes signos linguísticos possuem uma estrutura comum a todos, composta de dois elementos permanentes e universais, o significante e o significado" (PUPPI, 2009, p. 75). Por isso no desenvolvimento das atividades pedagógicas e sociais do âmbito escolar, os professores e alunos precisam usar a LIBRAS nas suas interações.

Neste sentido, buscamos a definição peirciana da linguagem através dos signos, ou semiótica, a ciência que se constitui em torno dos fatos da linguagem, "abrangendo não somente a língua falada como também a escrita e todo o universo dos signos e das linguagens não verbais" (PUPPI, 2009, p. 115-116). Entende-se que todo pensamento é contextualizado através dos signos. O estudo dos signos é realizado pela semiótica, ciência que estuda as leis 


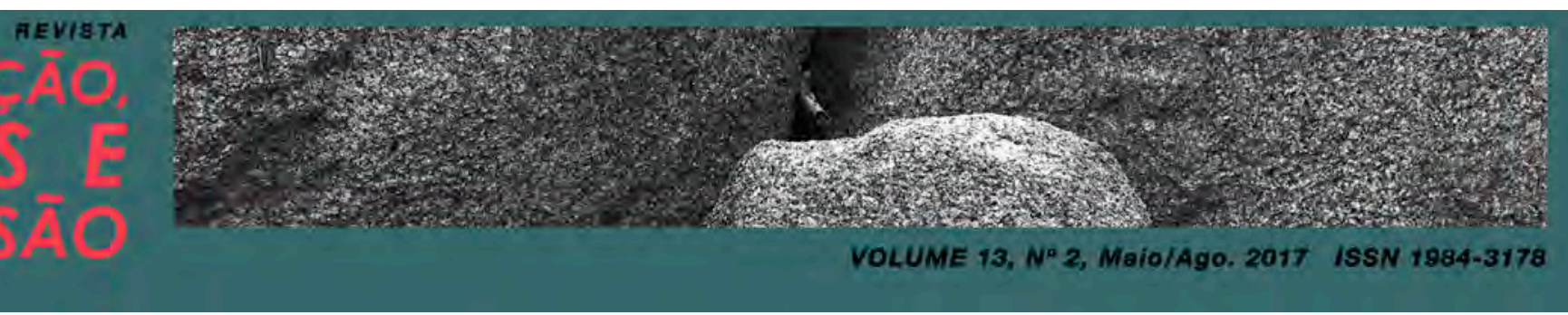

gerais dos signos. Sendo assim, Puppi conclui que a arte é uma linguagem, isto é que "pode haver um modo de compreender o fenômeno da linguagem como um todo que nos permite incluir o fenômeno artístico como uma de suas manifestações particulares” (PUPPI, 2009, p. 30). A partir de toda esta discussão concluímos que, a língua de modalidade gesto-visual da Libras em contato com a arte, sendo esta também uma forma de linguagem, nossa hipótese é que pode contribuir bastante para a comunicação entre os sujeitos envolvidos no ambiente de uma escola bilíngue e assim o diálogo relevante entre os indivíduos.

O ensino de arte deve propor a apreciação estética para permitir que a criatividade possa ser exercitada. E esta proposta perpassa pela alfabetização visual, ou seja, uma nova maneira de "ver, perceber, reconhecer ler, contemplar, enfim... olhar [...] sugerir uma exploração desse olhar" (BUENO, 2008, p. 12). Pois bem, é ai que entra a leitura de imagens, a apreciação da obra de Arte, seu significado de alcance privilegiado ao aluno que precisa compreender um mundo feito de imagens. "A experiência da observação serve, não apenas como recurso que nos permite aprender, mas também atua como nossa mais estreita ligação com a realidade de nosso meio ambiente. Confiamos em nossos olhos e deles dependemos" (DONDIS, 2007, p. 3).

E para o aluno surdo é extremamente relevante sua capacidade de ver assim este aluno precisa ser orientado a ver, precisa de que sua capacidade de observação seja ampliada para que suas dificuldades sejam minimizadas. Este papel deve ser desempenhado pelos professores, mas o professor de Arte tem uma preponderância enorme sobre as outras disciplinas, pois é através principalmente das Artes Visuais que este potencial irá ser não só despertado, mas, infinitamente ampliado.

[...] A capacidade de ver, reconhecer e compreender, em termos visuais, as forças ambientais e emocionais, superam os outros sentidos. Praticamente desde a nossa primeira experiência no mundo, passamos a organizar nossas necessidades e prazeres [...] com base naquilo que vemos. [...] Essa descrição não dá de forma alguma a exata medida do poder e da importância que o sentido visual exerce sobre nossa vida. Nós o aceitamos sem nos darmos conta de que ele pode ser aperfeiçoado no processo básico de observação, ou ampliado até converte-se num incomparável instrumento de comunicação humana (DONDIS, 1997, p. 5-6). 
Uma imagem diz mais que palavras, afirmação muito acertada no que tange o ensino de arte numa escola para surdos. E a aprendizagem por meio da leitura de imagens no ensino de arte é algo bastante dinâmico, pois:

[...]a prática que o percorrer do olho sobre a superfície plana da pintura acontecia mediante uma interação entre olho e objeto, em que o olho, num movimento contínuo sobre a materialidade da pintura, ia estabelecendo relações [...] e construindo significações geradas pelos significantes do texto visual. Assim, o olho do leitor percorre, no tempo e no espaço, um caminho ao longo do qual são geradas significações e são construídos sentidos (BUORO, 2003, p. 32).

É por meio das imagens de obras de arte que o aluno irá se apropriar de significados que, somando a suas próprias experiências irá não só enriquecê-lo, mas ampliar sua conexão com o mundo, bem como sua capacidade de observação aumenta gradativamente, além de seu entendimento sobre o mundo que o rodeia, sobre a sociedade através dos tempos, sobre as várias pessoas que construíram imagens que pudessem ser não só apreciadas, mas estudas e compreendidas numa leitura repleta de significações e na construção de uma releitura autoral de cada aluno. "A função de olhar não é simples. [...] Não basta abrir os olhos, precisamos exercitar nosso olhar, como fazemos com nosso cérebro ou nosso corpo"(BUENO, 2008, p.21). É preciso mais do que olhar, é preciso exercitar esse olhar para de fato aprendermos a ver e interpretar o mundo por meio das informações que o mundo nos oferece por meio de imagens.

\section{METODOLOGIA}

Este estudo teve início a partir dos questionamentos da docente sobre a realidade que se lhe apresentava no contexto da escola bilíngue para surdos. Este texto expressa uma iniciativa de investigação sobre os atores que estão diretamente ligados a este questionamento, onde pressupõe o conhecimento da realidade, neste caso, a realidade educacional.

Assim, este relato aborda temas como Arte e Inclusão, numa escola pública bilíngue para alunos surdos, propondo-se discutir as especificidades desse universo. Para o desenvolvimento desta proposta, optou-se por um estudo exploratório e descritivo, pois 


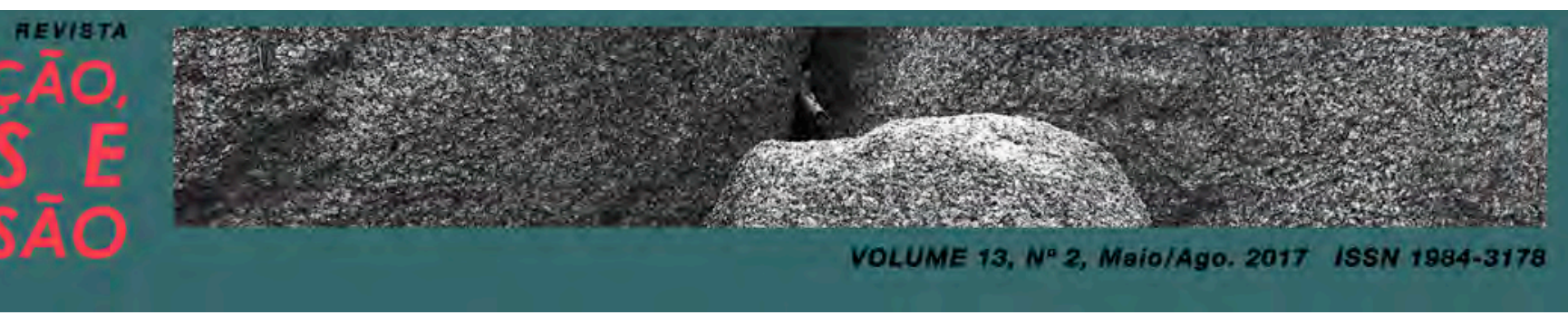

objetiva a descrição das características de determinada população e, por utilizar o ambiente natural como fonte direta para a coleta de dados, tendo a prática artística da leitura e releitura de imagens realizada pela professora com seis alunos surdos, bem como a construção das relações inerentes ao estudo e análise das interações que ocorreram entre os alunos e essa experiência artística por meio desse relato.

\subsection{Caracterizando a escola bilíngue}

A Escola Municipal Bilíngue em que ocorre a experiência relatada, a qual será nomeada “ARCO-ÍRIS”, fundada numa cidade do interior do Estado do Rio de Janeiro há 25 anos, foi criada pelo Decreto $\mathrm{n}^{\mathrm{o}} 125$ de 17 de julho de 1990, destinava-se a alunos surdos do $1^{\mathrm{o}}$ ao $9^{\mathrm{o}}$ ano do Ensino Fundamental, mas passou a matricular alunos ouvintes desde 2011. Este pseudônimo "Arco-Íris" foi criado para preservar a identidade dessa escola, e surgiu a partir da observação do espaço escolar onde trabalhos realizados pelos alunos e professores da unidade, priorizando e valorizando a capacidade ampliada e o valor visual da informação para os sujeitos que interagem neste ambiente. Esta instituição, segue a filosofia bilíngue, na qual a Libras (Língua Brasileira de Sinais) é a primeira língua do surdo e a Língua Portuguesa, na modalidade escrita, a segunda língua. No projeto integral, a escola oferece uma educação pautada na otimização das potencialidades do educando, na valorização e no respeito à diversidade sociocultural e linguística.

\subsection{Conhecendo a história da arte}

Assim, esta experiência oferece, através da leitura de imagens, a apreciação da obra de arte, seu significado de alcance privilegiado ao aluno surdo que compreende o mundo a partir informações imagéticas. "A experiência da observação serve, não apenas como recurso que nos permite aprender, mas também atua como nossa mais estreita ligação com a realidade de nosso meio ambiente. Confiamos em nossos olhos e deles dependemos" (DONDIS, 2007, p. 3). A observação deste mundo feito de imagens será orientada, nesta experiência, por uma prática pedagógica da disciplina de arte pautada na abordagem triangular, a qual permite o conhecimento da história da arte, um fazer artístico baseado na leitura e interpretação destas 
informações, neste caso, do movimento artístico impressionista. Ainda sobre a compreensão das informações das imagens na arte, Dondis (1997) comenta: "O modo visual constitui todo um corpo de dados que, com a linguagem, podem ser usados para compor e compreender mensagens (...) desde o puramente funcional até os mais elevados domínios da expressão artística" (DONDIS, 1997, p. 3).

O papel de orientar a compreensão das informações contidas nas imagens deve ser desempenhado pelos professores, mas o professor de arte tem uma preponderância enorme sobre as outras disciplinas, pois é por meio principalmente das Artes Visuais que este potencial irá, não só ser despertado mas, infinitamente ampliado.

(...) A capacidade de ver, reconhecer e compreender, em termos visuais, as forças ambientais e emocionais, superam os outros sentidos. Praticamente desde a nossa primeira experiência no mundo, passamos a organizar nossas necessidades e prazeres (...) com base naquilo que vemos. (...) Essa descrição não dá de forma alguma a exata medida do poder e da importância que o sentido visual exerce sobre nossa vida. Nós o aceitamos sem nos darmos conta de que ele pode ser aperfeiçoado no processo básico de observação, ou ampliado até converte-se num incomparável instrumento de comunicação humana (DONDIS, 1997, p. 5-6).

Nesse sentido, valorizar e promover o desenvolvimento dessa capacidade com alunos surdos no ensino da arte, parece ser possível.

Este relato vem trazer uma experiência sobre a proposta ou abordagem triangular de Ana Mae Barbosa, a qual postula que o conhecimento sobre a história da arte deve ser realizado de forma crítica, por meio de uma leitura e releitura de imagens e um fazer artístico a partir do conhecimento adquirido por este processo, ou seja, contextualização histórica (conhecer a sua contextualização histórica); fazer artístico (fazer arte); apreciação artística (saber ler uma obra de arte). Nas aulas de arte da atualidade estão sendo oportunizadas propostas como a leitura de imagens, bem em sintonia com um mundo, cujas imagens são veículo de informação em toda parte, onde quer olhamos, e fazer uma leitura das mesmas torna-se fundamental para a compreensão do mundo onde vivemos. "É preciso que o aluno seja 'alfabetizado' para ler as imagens que se apresentam em seu cotidiano, e o estudo das obras de arte (incluindo as do passado) torna-se um facilitador nesse processo" (CORTELAZZO, 2008, p.12). Assim, a experiência de que trata este relato ocorreu a partir 
das aulas de Arte numa escola bilíngue, no ano de 2014 com os alunos surdos João, Luciano, Maria, Patrícia, Guilherme e Lúcio Mauro, cujo conteúdo programático a ser trabalhado teve como tema o movimento artístico denominado impressionismo.

A proposta triangular se efetivou com os alunos conhecendo o movimento impressionista como um período na história da arte, tendo algumas obras e seus respectivos artistas apresentados a eles, primeiramente com livros. Enquanto os alunos manuseavam os livros, toda a descrição das principais características dos artistas e do movimento impressionista era realizada a partir da mediação da interprete, que fazia a tradução/interpretação da língua oral utilizada pela professora para Libras. Destaca-se, que a partir do acesso a informação, possível por meio da Libras, o interesse e participação dos alunos foi estabelecida.

Esteticamente, para apreciarmos uma obra, necessitamos de um certo domínio dos conceitos básicos de uma composição. Mas se nosso objetivo transcende às características gerais em uma pintura ou desenho, em nosso trabalho também se faz necessário um estudo de iniciação à história da arte (BUENO, 2008, p. 19).

Em seguida, para conhecer mais imagens que não havia nos livros " $\underline{\text { Os }}$ Impressionistas", foram projetadas com auxílio de multimídia, diversos exemplos de obras deste movimento. Nesse momento, os alunos puderam observar as imagens, e perceber nelas as características dessas pinturas, e assim tecer opiniões e significados sobre as mesmas. tais como: "essa pintura é bonita, gosto dela"(Guilherme.); "Muito legal, é colorido"(João); "gosto de pinturas, de paisagens"(Luciano); as opiniões dos alunos expõem como eles reagiram sobre o que lhes era apresentado. "Onde foi feita essa pintura, que lugar?(Maria); “Como o artista fez?"(Guilherme). Esta fase constitui-se na proposta aquela que o aluno conhece e se apropria do que tomou conhecimento: as informações visuais se codificam em informações conceituais.

Assim, recapitulando, estas perguntas foram sendo esclarecidas (sempre mediadas pela interprete de Libras) no momento que surgiam e diante da obra que as suscitou. "O fato é: quanto mais informações tivermos sobre uma determinada imagem, mais subsídios teremos para analisá-la"(BUENO, 2008, p. 19-20). Por meio das imagens de obras de arte que o aluno 


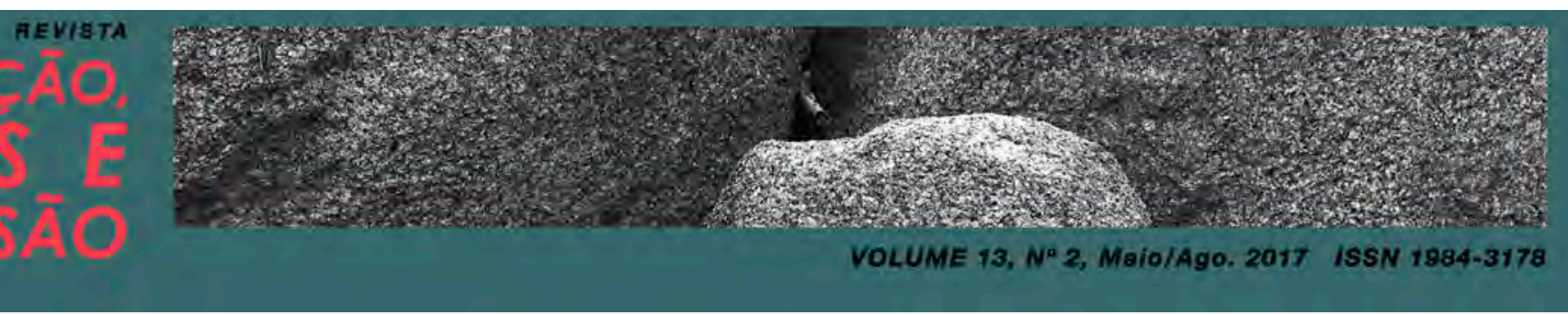

pode se apropriar de significados que, somando a suas próprias experiências não só o enriquece, mas amplia sua conexão com o mundo, bem como sua capacidade de observação, além de seu entendimento sobre o ambiente que o rodeia, sobre a sociedade através dos tempos, associando as imagens do passado com seu presente; sobre as várias pessoas que construíram imagens que pudessem ser não só apreciadas, mas estudadas e compreendidas, numa leitura repleta de significações e na construção de uma releitura autoral de cada aluno, quando os mesmos vão construir suas próprias imagens inspirados e estimulados pelas reflexões que estas obras lidas permitiram. Em seguida, aproveitando o interesse por determinadas obras e artistas, a proposta triangular tem continuidade, quando o aluno contextualizou as informações adquiridas por meio das imagens, relacionando a suas próprias experiências.

É dessa forma que o conhecimento sobre uma imagem soma-se ao conhecimento de mundo e relaciona-se. Um enriquecendo o outro, e o olhar se ampliando nesta busca de compreender e refletir, porque ler uma imagem significa compreendê-la, interpretá-la. $\mathrm{O}$ conhecimento em arte se dá a partir dessas ações para que o indivíduo possa se expressar sobre o que compreendeu nesse processo. "Na arte, os significados são imediatamente dados não porque o conteúdo não seja mediado, mas porque é reflexivo, fazendo a atenção volta-se para a forma e a matéria que o expressam. Essa reflexividade é a expressão" (DEWEY, 2010, p. 40). Refletindo sobre a necessidade de se adaptar e transformar esse conhecimento adquirido significativamente, através da vivência do ensino e da aprendizagem em sala de aula que devemos disponibilizar os vários meios de experimentação, o fazer artístico a partir da apropriação deste conhecimento, que a arte, através de suas várias linguagens vai disponibilizar os meios para tal experiência.

Toda obra de Arte tem um meio particular pelo qual, entre outras coisas, o todo qualitativo e penetrante é transmitido. Em toda experiência, tocamos o mundo através de um tentáculo específico; realizamos nossa interação com ele e ele chega até nós por um órgão especializado. O organismo inteiro, com toda a sua carga do passado e de recursos variados, funciona, mas opera por um meio particular, o dos olhos, ao interagir com o olhar, a audição e o tato. As Artes lançam mão disso e o levam ao máximo de significação (DEWEY, 2010, p. 352). 


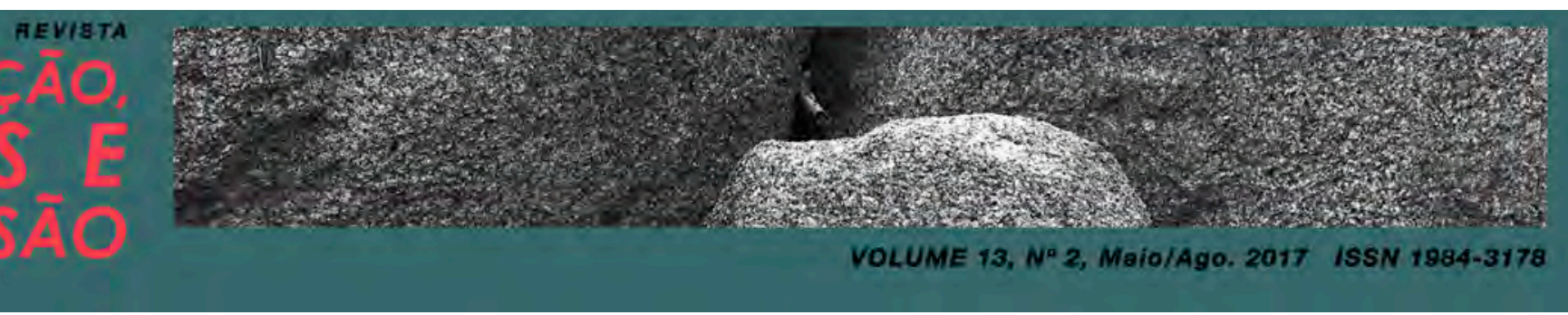

“A proposta da maioria dos impressionistas era a pintura ao ar livre [...] deixaram de lado os grandes temas para pintar motivos como a chuva, [...] ou simplesmente os efeitos da variação da luz sobre a paisagem" (CORTELAZZO, 2008, p. 70). Havia entre estes artistas a intenção de estudar a cor sob a variação da luz, como principal objetivo. A ausência de contorno na pintura fazia com que a apreciação das obras fosse feita a certa distância da tela. Todas estas informações foram transmitidas aos alumos por meio da Libras, que precisavam de bastante detalhe por parte da intérprete para sanr qualquer dificuldade na compreensão dos conceitos apresentados.

É neste momento que a proposta triangular se encaminhou para sua fase de contextualização das informações adquiridas por meio das imagens: as obras selecionadas para os alunos deste estudo foram observadas e apreciadas por eles em reproduções nos livros dos artistas (ALZUGARAY; CARTA; FASANO, 1973) e imagens pesquisadas na internet reproduzidas em aparelho de multimídia e projetor que permitiu a ampliação dessas imagens para sua melhor percepção. Um exemplo dessa leitura foi a apresentação da imagem "O Sena visto da Grande Jatte", paisagem cuja técnica impressionista utilizou o pontilhismo.Os comentários da docente sobre a imagem foram de que se tratava de obra do artista Georges Seurat, cuja paisagem retrata o rio Sena, visto de uma ilha chamada Jatte, na França, onde os alunos, contextualizando esta imagem, associaram seus conhecimentos a lembrança de que na cidade onde residem teve, por breve período, passeio de barco no rio, e que a ilha lembrava o parque da cidade, bem próximo deste rio; a seguir, as questões plásticas, isto é, a materialidade e técnicas de pintura foram trazidas como estudo das cores complementares desenvolvidas por estes artistas, já introduzidas e desenvolvidas pelos alunos em exercício de pintura para maior compreensão de que a luz influencia na cor, em determinadas horas do dia, e isto se verificou através de experiência de observação por eles experimentadas em tarefa para este fim, (observação de uma mesma área (paisagem) por três momentos distintos do dia: amanhecer, ao meio dia e final da tarde) e que, a partir destas observações, propiciaram o entendimento das imagens que foram sendo analisadas uma após a outra. A seguir algumas obras e seus respectivos artistas: 

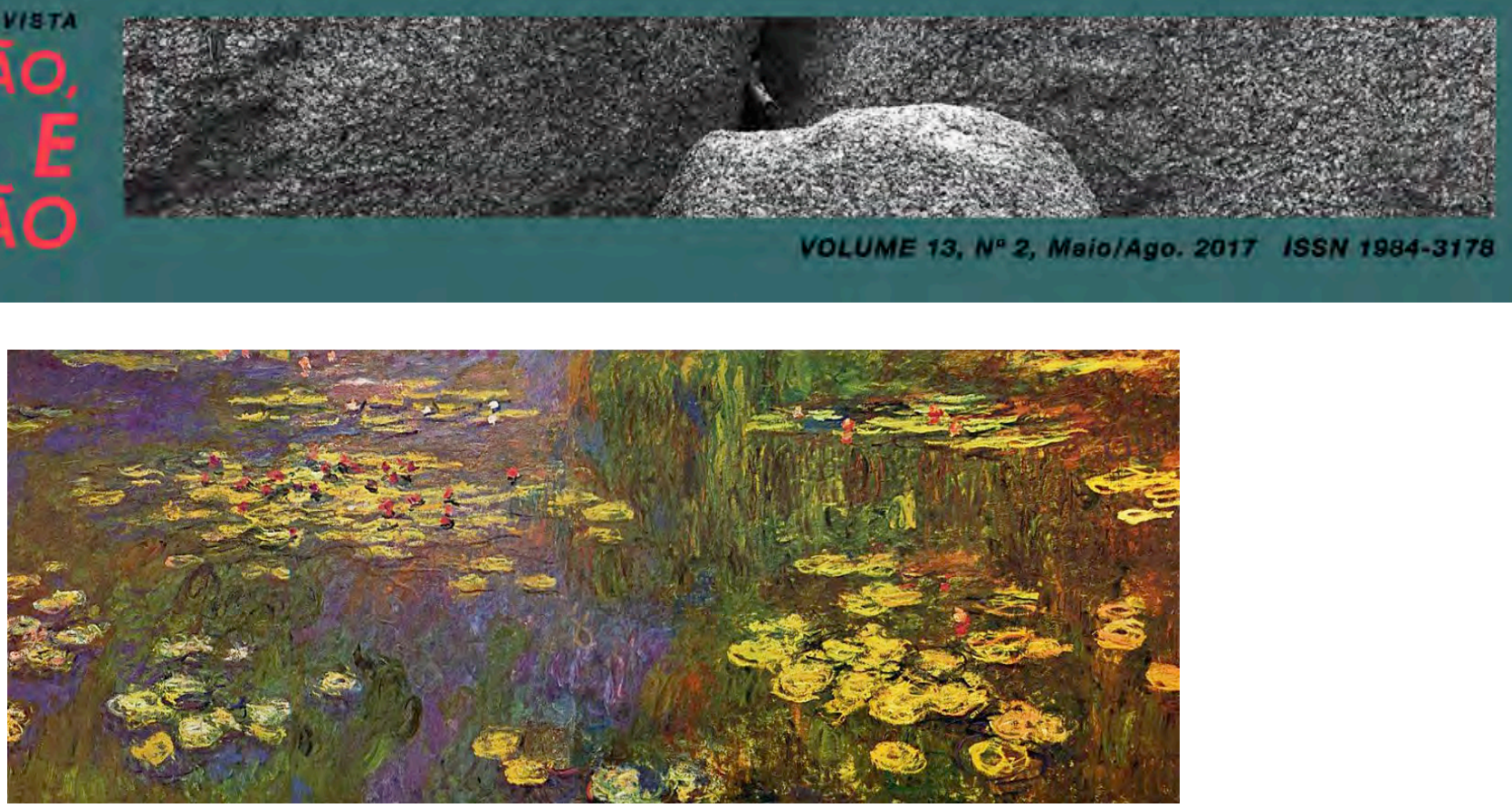

Figura 01 - O lago das Ninféias. Autor: Claude Monet. Ano: 1919 - Fonte: Os Impressionistas, 1973.(livro)

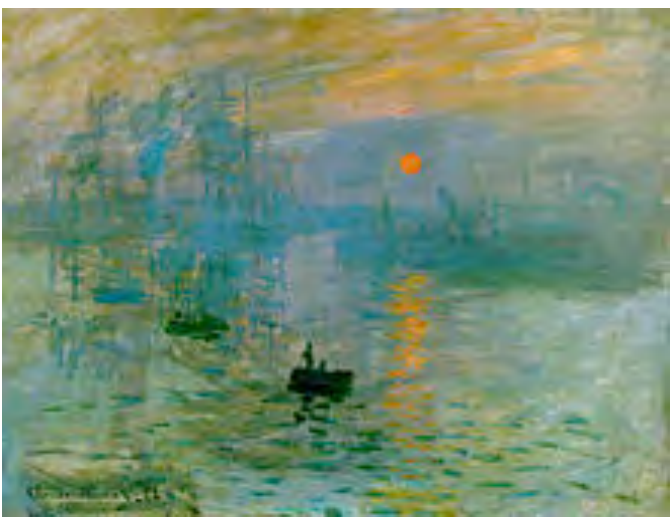

Figura 02: Impressão, nascer do sol. Autor: Claude Monet. Ano: 1873, p. 26

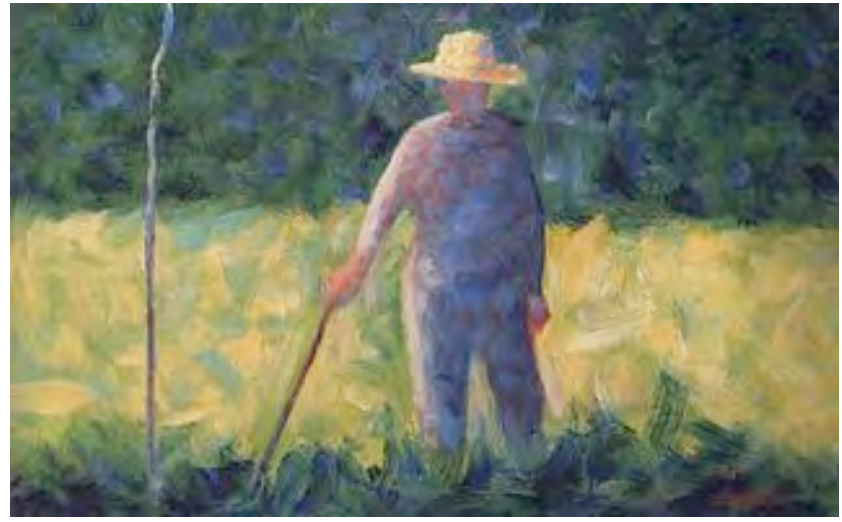

Figura 03: O jardineiro. Autor: Georges Seurat. Ano: 1882, p.18 


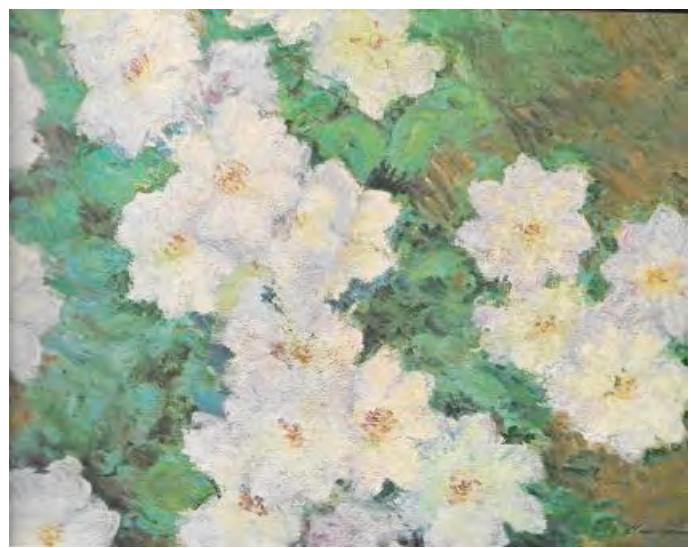

Figura 04 - Flores. Autor: Claude Monet. Ano: 1887 , p. 53

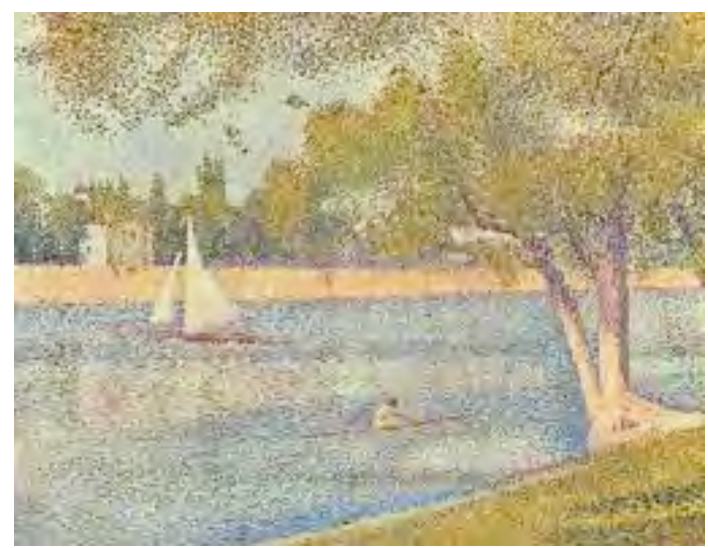

Figura 05: O Sena na Grande Jatte, primavera. Autor: Georges Seurat. Ano: 1888 , p. 48

Fonte: Os Impressionistas, 1973. (livro)

Assim sendo, após a docente apresentar aos alunos as informações já descritas anteriormente, os mesmos foram escolhendo as imagens das obras dos artistas por afinidade, por lembranças de algo em sua própria memória visual, a partir de suas experiências pessoais, como por exemplo:

“jardim e flores, minha casa tem um igual também”(Luciano), sobre $O$ lago das ninféias de Monet, ou "o barco, o passeio no Rio daqui da nossa cidade"(Maria), quando as obras de Seurat da Ilha de Grande Jatte foram apresentadas. Ou ainda (João) quando revela que "o trabalho do homem no campo, viu igual perto da casa dele [...] Fazenda da Barra," em $O$ jardineiro de Seurat.

A partir das observações e da participação da intérprete de Libras para os conceitos mais específicos, como para auxiliá-los, como a palavra "movimento" impressionista que significa o mesmo que arte impressionista ou impressionismo, entretanto, neste contexto, a palavra movimento tem outro significado, dificultando a compreensão de alguns dos alunos do que seria o movimento do corpo na dança por exemplo. Sanada a dúvida pela intérprete, outras questões surgiram como a necessidade destes artistas de estudar desta forma naquele 


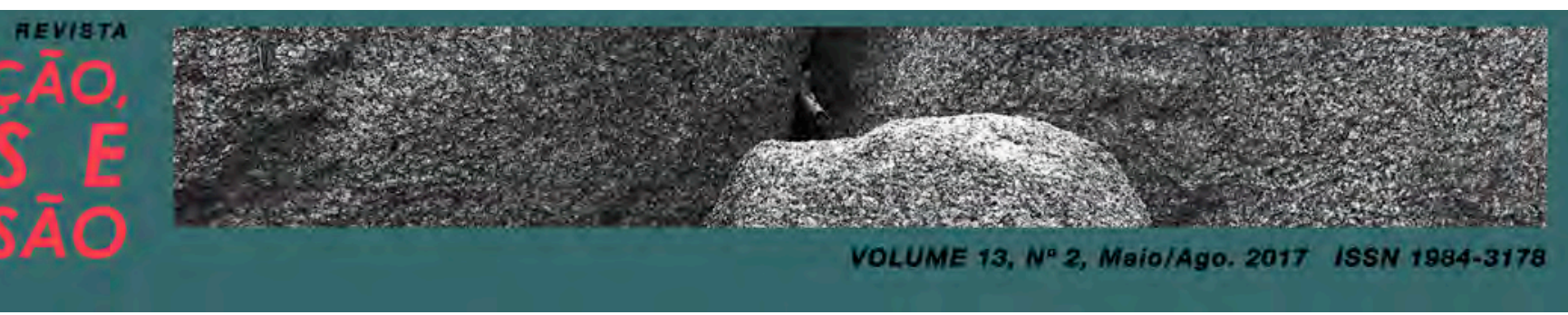

momento, os porquês disto, também explicado pelo advento da fotografia, o que deixou os alunos bastante interessados pois todos eles são bem familiarizados pela arte da fotografia por meio de seus celulares. Dizer que a fotografia começou lá no início do séc.XIX também fez com que estes alunos contemplassem as relações temporais, questões estéticas e plásticas estudadas naquele momento do passado, costumes de época como roupas apresentados nas obras, bem como as características marcantes trazidas pelo impressionismo que era o estudo da cor através da luz ambiente, sua inconstância e sua vaporosa evanescência. Depois de observar e debater sobre as obras apresentadas, os alunos deveriam escolher uma obra/artista que lhes chamasse atenção e a partir das relações desta escolha, fazer uma releitura ou interpretação pessoal desta obra escolhida, o que denominamos na proposta triangular como fazer artístico, aquele que finaliza a proposta que tem como princípios norteadores já percorridos: ler para conhecer, contextualizar seu significado em sua experiência pessoal reler para concretizar no fazer artístico:

O fazer artístico é insubstituível para a aprendizagem da arte e para o desenvolvimento do pensamento/linguagem presentacional, uma forma diferente do pensamento /linguagem discursivo, que caracteriza as áreas nas quais domina o discurso verbal, e também diferente do pensamento científico presidido pela lógica. $O$ pensamento presentacional das artes plásticas capta e processa a informação através da imagem (BARBOSA, 1999, p. 34).

Assim, os alunos, depois de conhecerem as imagens das obras apresentadas, escolheram aquelas que lhes trouxeram significado pessoal, como o aluno João que escolheu Flores de Monet por esta imagem lembrar as inúmeras flores que conhece e que possui em sua casa; O Sena na Grande Jatte, primavera de Seurat, escolhida por vários alunos, entre eles estão Maria, Patrícia e Guilherme, pois que a obra remetera ao "rio da cidade e também do barco que ali havia" (Guilherme); ou $O$ jardineiro de Seurat, que foi eleita pelo aluno Luciano, por ligar a suas memórias da zona rural onde mora/reside.

É importante que o aluno tenha espaço para fazer sua própria análise [...] sua opinião deve ser valorizada [...] à medida que se familiarizar com as obras, conseguirá fazer relações de maneira mais espontânea e natural e tomar posicionamentos cada vez mais críticos (CORTELAZZO, 2008, p. 12). 
É pelo exercício do olhar sobre a imagem que pode haver a percepção do seu conteúdo e seu significado. E para que esse olhar faça conexões significativas, é preciso que observe, interprete, elabore e reflita sobre seu significado.

Dois pintores participaram da última exposição impressionista em 1886: Georges Seurat e Paul Signac. Podemos dizer que estes artistas aprofundaram as pesquisas dos impressionistas em relação a percepção óptica. Utilizando apenas cores primárias, eles conseguiram fazer com que através de pontos, a imagem fosse captada de uma maneira total. É possível termos a ideia de como isso acontece no quadro de Seurat Tarde de Domingo na Ilha de Grande Jatte. Nesta tela, o pintor transpõe a imagem de uma tarde de domingo de um local popular, numa ilha do rio Sena, com pinceladas reduzidas a pontos [...] ao olharmos a certa distância nem percebemos que são pequenos pontos uniformes (BUENO, 2008, p. 27).

As escolhas dos alunos foram feitas a partir das suas observações, onde os mesmos realizaram vários desenhos e pinturas, apropriando-se dos conhecimentos adquiridos e ressignificando-os em imagens, nas suas releituras. Seus trabalhos foram realizados em seus cadernos de desenho, depois em cartolinas, pintados com tinta guache e pincéis, e um destes trabalhos, "O Sena visto da Grande Jatte" foi pintado com guache na cartolina por Maria, Patrícia e Guilherme., primeiro com o pincel batido em pontos, depois os alunos resolveram que o terminariam utilizando as pontas dos dedos, numa releitura pontilista bastante interessante, atitude que reflete seu protagonismo no fazer artístico. "Muitos artistas desse período passaram a aplicar a tinta diretamente na tela, sem misturá-las na paleta, pois a agilidade era importante para que captassem a variação e o movimento da luz" (2008, p. 70).

Assim se concretiza a proposta triangular de Ana Mae Barbosa para o ensino de arte: "o conhecer" através da leitura da imagem da obra de arte, o "fazer artístico" contextualizado pelo conhecimento adquirido na releitura da obra lida.

Quando o aluno observa obras de arte e é estimulado e não obrigado a escolher uma delas como suporte de seu trabalho plástico, a sua expressão individual se realiza da mesma maneira que se organiza quando o suporte estimulador é a paisagem que ele vê [...] $\mathrm{O}$ importante é que o professor não exija representação fiel, pois a obra observada é suporte interpretativo e não modelo para os alunos copiarem (BARBOSA, 1999, p. 107). 
A releitura enquanto fazer artístico significa refazer a obra novamente, reconstruindo-a com novas informações ou retirando aquelas que o sujeito achar conveniente. Não é copiar, pois que esta reproduz e isto não significa aprender ou compreender, é mecânico, sem propósito. "Uma releitura significa se apropriar de conhecimentos adquiridos sobre a imagem lida e as informações inerentes a ela e o artista que a produziu" (SILVA, 2009, p. 39).

As releituras dos alunos realizadas nesta proposta foram expostas na própria escola bilíngue Semana da Pessoa com Deficiência realizada no final de agosto de 2015, para a apreciação e valorização da comunidade escolar. A seguir algumas das releituras dos alunos:

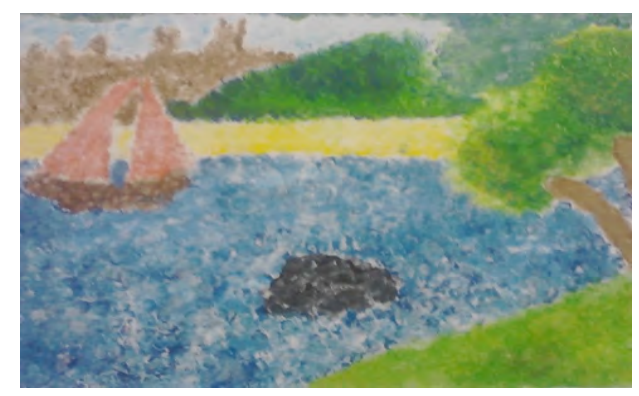

Figura 06: Releitura de “O Sena na Grande Jatte”, primavera, 1888. Alunos(as) Maria, Patrícia e Guilherme.

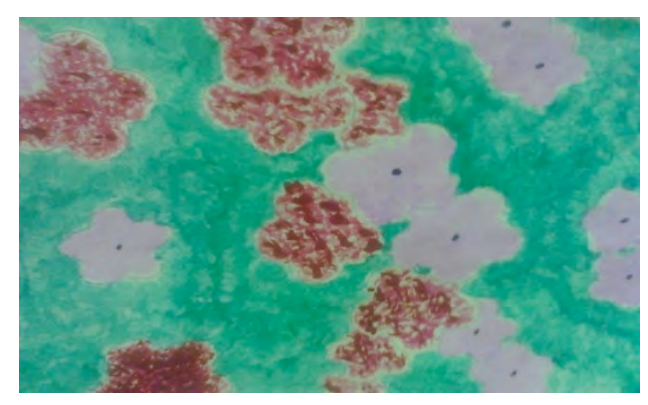

Figura 07: Releitura de Flores, de Monet, 1887. 


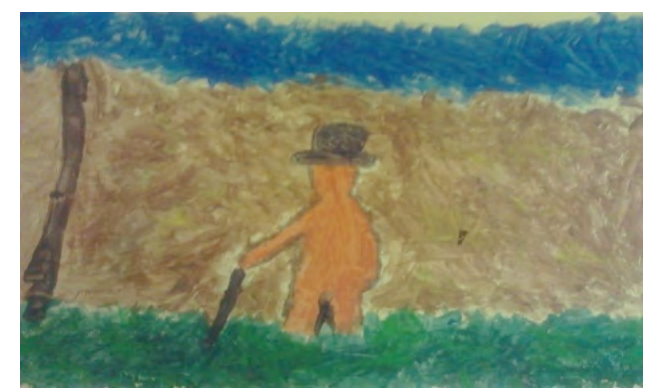

Figura 08: Releitura de O Jardineiro, Monet, 1882.

do aluno Luciano.

\section{CONCLUSÃO}

Esta experiência apresentou primeiramente, o movimento impressionista aos alunos por meio de obras dos diversos nomes do movimento impressionista, perfazendo a proposta triangular de ana Mae Barbosa que consiste em conhecer a história da Arte por meio da leitura de imagens, concluindo a mesma com o fazer artístico contextualizado na releitura dessas imagens. Os principais resultados apontaram que a educação inclusiva bilíngue é um desafio sob os diferentes aspectos, desde a comunicação até sua aplicação, mas a adaptação do currículo não só é viável quanto imprescindível para que o conhecimento e a aprendizagem se efetivem na escola bilíngue. Docentes e comunidade escolar puderam perceber que a disciplina de Arte, tem muito o que contribuir para aa educação do surdo, ampliando sua percepção visual, abrindo novas possibilidades para a apropriação de saberes e assim, conquistar, cada vez mais seu direito de aprender, conquistando também sua cidadania.

\section{REFERÊNCIAS}

ALZUGARAY, Domingo; CARTA, Luis \& FASANO, Fabrizio. Biblioteca de Arte - Os Impressionistas. São Paulo: Três, 1973. 
BARBOSA, Ana Mae. A imagem no ensino da arte. São Paulo: Perspectiva, 1999.

BUENO, Luciana Estevam Barone. Linguagem das Artes Visuais. Curitiba: Ibpex, 2008.

BUORO, Ana Amélia Bueno. Olhos que pintam: A leitura da imagem no ensino da arte. $2^{\mathrm{a}}$ ed. São Paulo: Educ/Cortez, 2003.

CORTElazZO, Patrícia Rita. A História da Arte por meio da Leitura de Imagens. Curitiba: Ibpex, 2008.

DEWEY, John. Arte como Experiência. Tradução Vera Ribeiro. São Paulo: Martins Fontes, 2010.

DONDIS, A. Dondis. Sintaxe da Linguagem Visual. 2a ed. São Paulo: Martins Fontes, 1997.

IMBROISI, Margaret H.; MARTINS, Simone R. História da Arte - Linha do Tempo Impressionismo. Apresenta reproduções virtuais de obras de artistas dos movimentos estéticos na história da arte. 1998. Disponível: http://www.historiadaarte.com.br/linha/impressionismo.html. Acessado em: 09-09-2015.

SILVA, Maria Cristina Rosa Fonseca.(Org.) A inclusão na fala do professor de arte: recortes da cultura escolar. In: Educação Arte e Inclusão: Trajetórias de Pesquisa. Florianópolis: UFSC, 2009.

PUPPI, Alberto. Comunicação e semiótica. Curitiba: Ibpex, 2009.

SANTOS, R. A.; MENDONÇA, S. R. D.; OLIVEIRA, M. C. A instituição especializada em tempos de inclusão. Revista Educação Especial. Santa Maria. v. 27, n. 48, p. 41-52, jan. abr. 2014. Disponível: <http://www.ufsm.br/revistaeducacaoespecial>. Acesso em: 11 de janeiro de 2016.

SKLIAR, Carlos. Bilingüismo e Biculturalismo. Uma análise sobre as narrativas tradicionais na educação dos surdos. Caxambu: ANPED, 1998.

VYGOTSKY, L. S. Diagnóstico do desenvolvimento e clínica pedológica da infância difícil. [Esquema de investigação pedológica]. Tradução das partes 5 e 6 de: VIGOTSKI, L. S. Diagnóstico del desarollo y clínica paidológica de la infancia difícil. In: Obras Escogidas. Tomo 5 fundamentos de defectología. Madrid: Visor y Ministério de Educación y Ciencia, 1997. p. 275-338. Disponível em: <www.4shared.com/file/55971081/d96ff395/Vigotski>. Acesso em: 24 de julho de 2015.

VYGOTSKY, L. S. Psicologia da Arte. Tradução de Paulo Bezerra. São Paulo: Martins Fontes, 1999.

ZABALZA, M. Diários de Aula: um instrumento de pesquisa e desenvolvimento profissional. Porto Alegre: ARTMED, 2004. 